\title{
BLICKDIAGNOSE
}

\section{Ungewöhnlicher (Be-)Fund im Thorax-CT}

Eine 68-jährige Patientin kommt zur stationären Aufnahme bei progredienter Dyspnoesymptomatik. Klinisch fällt bei der Patientin vor allem ein massives Übergewicht auf (GröBe 1,55m, Gewicht $160 \mathrm{~kg}$, BMI 66,6 kg/ $\mathrm{m}^{2}$ ). Weiterhin leidet sie unter verschiedenen adipositasassoziierten Erkrankungen, u.a. auch einem Adipositas-Hypoventilations-Syndrom.

— Im Rahmen der Abklärung der Dyspnoesymptomatik erfolgt eine Computertomografie des Thorax (Abbildung). Hier findet sich eine hyperdense Struktur, die sich auf den Bereich des Magens projiziert.

Bei genauerem Nachfragen erklärt die Patientin, dass sie vor einiger Zeit eine Zahnprothese über mehrere Zähne verloren hat und auch schon befürchtet hatte, diese verschluckt zu haben. In der Folge wird die Patientin an eine Klinik für Gastroenterologie überwiesen, wo die Zahnprothese komplikationslos endoskopisch entfernt werden kann.

Keywords: ingestion of a foreign body

- Dr. med. Christian Jung, Dr. med. Alexander Pfeil, PD Dr. med. Andreas Hansch, Klinik für Innere Medizin I der Universitätsklinik Jena, Erlanger Allee 101, D-07747 Jena

Unsere Blickdiagnosen finden Sie auch im Internet unter:

http://www.springermedizin.de/ blickdiagnosen-aus-der-praxis/307330.html
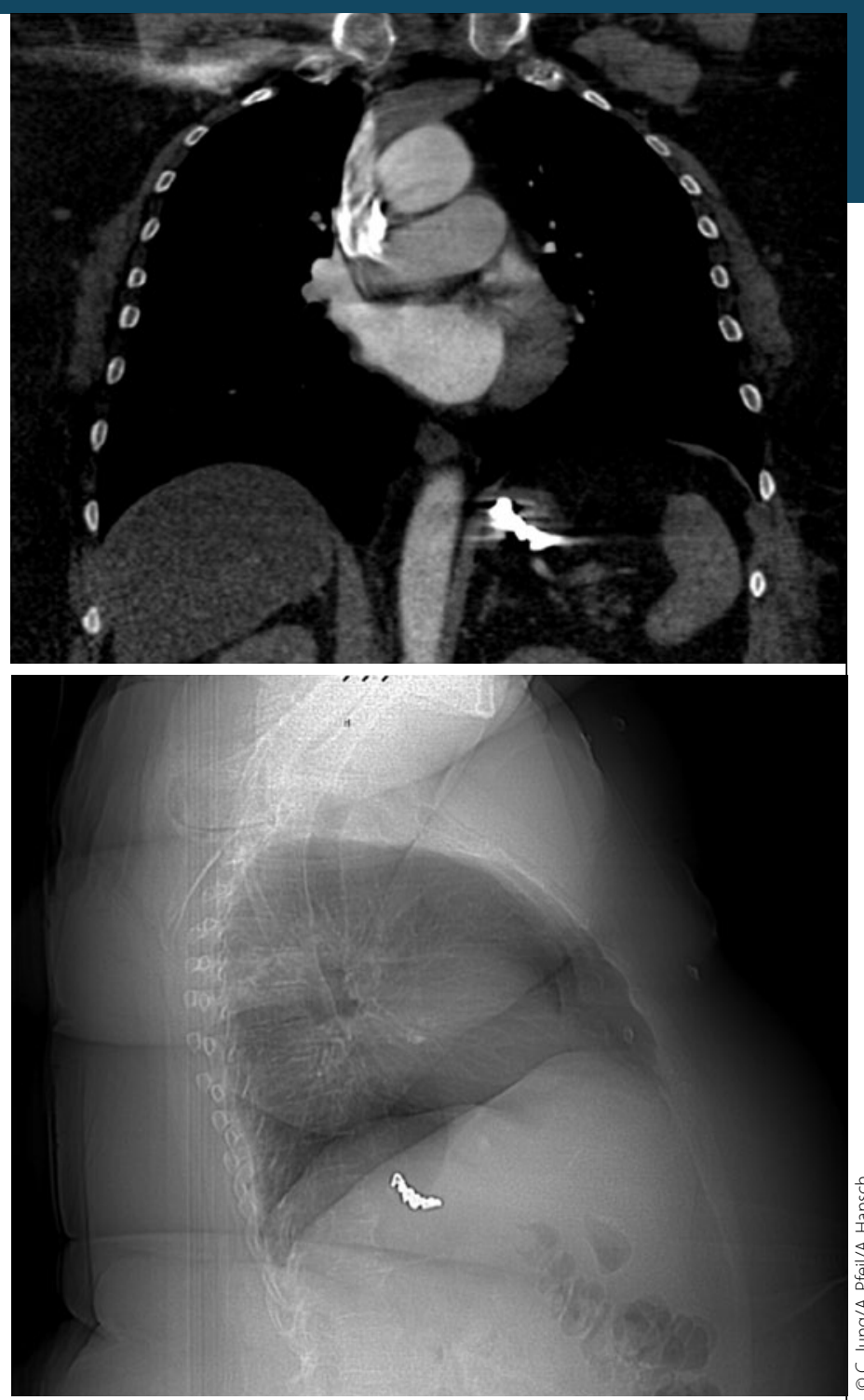

\section{Ihr besonderer Fall?}

\section{Stellen Sie uns Ihren Fall vor}

Sicher sehen auch Sie ab und an einen besonders eindrucksvollen Befund in Ihrer Praxis. Fotografieren Sie inn, schreiben Sie uns unter dem Stichwort Blickdiagnose, bei Veröffentlichung erhalten Sie 100 Euro.

\section{MMW-Fortschritte der Medizin}

E-Mail: reinhold.manhart@springer.com

Fax: 089/203043-31424 